\title{
BULLYING OF EXTREMELY LOW BIRTH WEIGHT CHILDREN: ASSOCIATED RISK FACTORS DURING ADOLESCENCE
}

\author{
Grace Yau, BS ${ }^{1}$, Mark Schluchter, $\mathrm{PhD}^{2}$, H. Gerry Taylor, PhD ${ }^{1}$, Seunghee Margevicius, \\ MA $^{2}$, Christopher B Forrest, MD.PhD ${ }^{3}$, Laura Andreias, MD.MS. ${ }^{1}$, Dennis Drotar, PhD $^{4}$, Eric \\ Youngstrom, $\mathbf{P h D}^{5}$, and Maureen Hack, MBChB ${ }^{1}$ \\ ${ }^{1}$ Department of Pediatrics, Case Western Reserve University, Cleveland, Ohio. \\ ${ }^{2}$ Department of Epidemiology and Biostatistics, Case Western Reserve University, Cleveland, \\ Ohio. \\ ${ }^{3}$ Children's Hospital of Philadelphia, University of Pennsylvania School of Medicine, Philadelphia, \\ Pennsylvania. \\ ${ }^{4}$ Cincinnati Children's Hospital Medical Center, University of Cincinnati College of Medicine, \\ Cincinnati, Ohio. \\ ${ }^{5}$ Department of Psychology, University of North Carolina at Chapel Hill, NC.
}

\begin{abstract}
BACKGROUND—Preterm children have many risk factors which may increase their susceptibility to being bullied. AIMS: To examine the prevalence of bullying among extremely low birth weight (ELBW, $<1 \mathrm{~kg}$ ) and normal birth weight (NBW) adolescents and the associated sociodemographic, physical, and psychosocial risk factors and correlates among the ELBW children.
\end{abstract}

METHODS—Cohort study of self reports of bullying among 172 ELBW adolescents born 1992-1995 compared to 115 NBW adolescents of similar age, sex and sociodemographic status. Reports of being bullied were documented using the KIDSCREEN-52 Questionnaire which includes three Likert type questions concerning social acceptance and bullying. Multiple linear regression analyses adjusting for sociodemographic factors were used to examine the correlates of bullying among the ELBW children.

RESULTS-Group differences revealed a non-significant trend of higher mean bullying scores among ELBW vs. NBW children (1.56 vs. 1.16, $\mathrm{p}=0.057$ ). ELBW boys had significantly higher bullying scores than NBW boys (1.94 vs. 0.91, p<0.01), whereas ELBW and NBW girls did not differ (1.34 vs. $1.30, \mathrm{p}=0.58)$. Bullying of ELBW children was significantly associated with subnormal IQ, functional limitations, anxiety and ADHD, poor school connectedness, less peer connectedness, less satisfaction with health and comfort, and less risk avoidance.

(C) 2012 Elsevier Ireland Ltd. All rights reserved.

CORRESPONDING AUTHOR Dr. Maureen Hack Rainbow Babies and Children's Hospital, University Hospitals of Cleveland Case Medical Center 11100 Euclid Avenue, Cleveland, Ohio 44106-6010 Telephone: 216-368-3744 Fax: 216-844-3380 mxh7@ case.edu. CONFLICT OF INTEREST STATEMENT

The authors have not declared any conflict of interest related to the current report.

Publisher's Disclaimer: This is a PDF file of an unedited manuscript that has been accepted for publication. As a service to our customers we are providing this early version of the manuscript. The manuscript will undergo copyediting, typesetting, and review of the resulting proof before it is published in its final citable form. Please note that during the production process errorsmaybe discovered which could affect the content, and all legal disclaimers that apply to the journal pertain. 
CONCLUSION_ELBW boys, but not girls, are more likely to be victims of bullying than NBW boys. School and health professionals need to be aware of the risk of bullying among ELBW male adolescents.

Peer victimization and bullying are major social problems prevalent among school-aged youth. Bullying is broadly accepted as a specific form of aggression consisting of the following characteristics: the behavior is intended to harm or disturb, it occurs repeatedly over time, and there is a disparity of power involving a more powerful person or group attacking a less powerful one. ${ }^{1,2}$ Victims of bullying may suffer from severe short and long term psychological consequences such as anxiety, depression, and eating disorders, as well as somatic consequences including headaches and sleep disturbance. ${ }^{3-6}$

There are many risk factors associated with being bullied. These include lower social class, poor social support, low self-esteem, short stature, and obesity as well as physical, psychosocial, and behavioral impairments. ${ }^{7-14}$ Preterm children tend to be smaller than their peers, have more internalizing and externalizing behavioral problems, and tend to be more socially isolated than normal birth weight children (NBW). ${ }^{15,16}$ They also demonstrate poor school performance with increased risk of grade repetition and special education placement. ${ }^{17,18}$ These personal and interpersonal characteristics may be accompanied by failed peer and group relationships which increase their risk of poor social acceptance and bullying.

There have been three reports of bullying among children and youth born prematurely, but none in the United States. ${ }^{19-22}$ Two of these studies reported increased rates of verbal bullying among preterm children as compared to NBW controls, ${ }^{19,21}$ whereas the third reported no differences. ${ }^{22}$

As part of a longitudinal study of extremely low birth weight (ELBW $<1 \mathrm{~kg}$ ) children, we sought to examine the occurrence of bullying among ELBW children compared with termborn NBW controls at age 14 years. We also sought to examine the sociodemographic, medical, and psychosocial correlates of bullying among the ELBW children. We hypothesized that ELBW children would experience significantly more bullying than NBW children. Based on studies of children in normal populations, ${ }^{7-14,23-27}$ we additionally hypothesized that increased bullying among the ELBW children would be associated with poor social support, low subjective well-being, ${ }^{9}$ anxiety and ADHD, ${ }^{7,12,13,25,26}$ and with poor health ${ }^{12-14,23}$ and short stature and obesity. ${ }^{10,11,27}$ Many of these problems have been reported in the cohort of ELBW children included in the present study. ${ }^{15,18,28}$

\section{METHODS}

\section{Extremely low birth weight population}

The study group included the survivors of 344 ELBW children admitted to the neonatal intensive care unit at Rainbow Babies and Children's Hospital, Cleveland, Ohio, during 1992-1995. Thirteen children (10 with major malformations, 2 with AIDS, and 1 with Tuberous Sclerosis) were excluded. Of the remaining 331 children, 238 survived of whom $181(76 \%)$ were followed to age 14 years. Nine children (seven with neurosensory impairments and eight with a subnormal IQ) did not complete the questionnaire concerning bullying resulting in a cohort of 172 ELBW children.

The 172 participants compared to the 66 surviving non-participants from the birth cohort had mothers with a significantly higher level of education (92\% vs. 58\% had completed high school, $\mathrm{p}<.001)$, lower rates of cerebral palsy ( $12 \%$ vs. $24 \%, \mathrm{p}<0.05)$, and were more likely to be female $(63 \%$ vs. $42 \%, \mathrm{p}<0.01)$. The participating and non-participating youth did not 
differ significantly with respect to maternal marital status, ethnicity, birth weight, gestational age, or rate of multiple births.

\section{NBW Children}

A comparison group of $176 \mathrm{NBW}$ children born at term gestation (>36 weeks) was randomly selected at the time of the 8 year study from the same school as the ELBW child and of the same sex, race, and age within 3 months. One hundred and fifteen (65\%) children were followed to age 14 years, all of whom responded to the bullying questionnaire. There were no differences in sociodemographic factors, rates of chronic conditions, or subnormal $(<70)$ IQ at age 8 years between the participants and the 61 children who did not participate.

\section{MEASURES}

\section{Child self-report questionnaires and assessments}

The primary outcome measure was the Social Acceptance and Bullying scale of the 10 dimensional European KIDSCREEN-52 health-related quality of life self-report questionnaire for children and adolescents aged 8 to 18 years. ${ }^{29}$ The Social Acceptance and Bullying dimension of this questionnaire pertains to certain aspects of feeling rejected by peers at school over a one week period. However, in the present study, we used a four week period to conform with the majority of the other questionnaires used in the study. The Social Acceptance and Bullying Dimension includes three questions: "Have you been afraid of other girls and boys?", "Have other girls and boys made fun of you?", and "Have other girls and boys bullied you?". Responses are made on a 5-point Likert scale [never (0), seldom (1), quite often (2), often (3), and always (4)]. An item level mean bullying score is computed from the three questions with higher scores indicating more bullying. The Social Acceptance and Bullying dimension has cross cultural relevance in developed nations and demonstrates acceptable convergent and discriminant validity and reliability (Cronbach's alpha of 0.77). ${ }^{29}$

Additional questionnaires completed by the children included those concerning health status, ${ }^{30}$ behavior, ${ }^{31}$ peer connectedness (friendships), ${ }^{32}$ and school connectedness. ${ }^{33}$ Health status was recorded with the Child Health and Illness Profile (CHIP-AE) which includes domains of Satisfaction, Comfort, Resilience, Risk Avoidance, Achievement, and Disorders. ${ }^{30}$ Behavior was measured with the Youth's Inventory-4 (YI-4) in which we examined both the symptom severity scores and DSM IV cut-off rates of Generalized Anxiety and the Inattentive, Hyperactive, and Combined types of ADHD. ${ }^{31}$ These were the most prevalent behavioral problems identified among the ELBW children. Peer connectedness was assessed using the mean score of three Likert type questions from the Healthy Pathways questionnaire with higher scores indicating stronger peer relationships. ${ }^{32}$ The questions selected include "How good are you at making friends?", "How many close male and female friends do you have?", and "How many days a week do you usually spend time with friends right after school?". School connectedness was assessed with the mean score of 5 questions from the National Longitudinal Study of Adolescent Health with higher scores indicating poorer connectedness. These questions include "feel close to people at this school", "feel like I am part of this school", "happy to be at this school", "teachers at this school treat students fairly", and "feel safe in my school". 33

All the questionnaires were self administered, however if the child could not read, the questions were read to them by a research assistant who was blinded as to the birth weight status of the child. The children also underwent psychometric testing including the Wechsler Abbreviated Scale of Intelligence (WASI) as a measure of IQ. ${ }^{34}$ A complete physical and neurologic examination had been completed at the time of the 8 year study. ${ }^{35}$ Weight and height were measured and obesity defined as a BMI $\geq 95^{\text {th }}$ percentile according to the CDC normative data. ${ }^{36}$ 


\section{Parent Questionnaires}

The parent or primary caregiver responded to questions concerning family sociodemographic descriptors and child health and behavior. Race was considered as a social construct and was self-identified by the parent from the list of racial/ethnic categories used for federal reporting. Chronic conditions were assessed via the shortened version of the Questionnaire for Identifying Chronic Conditions lasting 12 months or more (QUICCCR). ${ }^{37}$ The seven item Functional Limitation domain of the QUICCC-R was used to assess the child's physical, cognitive, emotional and social development. Parent reports of adolescent anxiety and ADHD were examined via the Adolescent Symptom Inventory $-4 .{ }^{38}$ Perinatal data had been recorded at the time of neonatal discharge and included birth weight, gestational age, multiple births and sex of the child.

The study protocol was approved by the Institutional Review Board of University Hospitals of Cleveland Case Medical Center. Written informed consent was obtained from the parents and written assent from the children.

\section{STATISTICAL ANALYSIS}

Comparisons of the mean bullying score and individual "bullying" questions between the total sample of ELBW and NBW children, and for boys and girls separately, were made using the Student's t test for continuous variables and chi-square test for categorical variables. Factors associated with being bullied among the ELBW children were examined using Pearson's correlation. Multivariable linear regression analyses were performed to examine significant correlates of bullying among the ELBW children after adjusting for sociodemographic factors including socioeconomic status (SES), race, and sex. Correlates examined included birth data, cerebral palsy at age 8 years, subnormal 14 year IQ, selfperceived health status as reported via the domains of the CHIP-AE, parent report of chronic functional limitations via the QUICCC-R, growth attainment at age 14 years (obesity, subnormal weight or height), parent and adolescent reports of behavior, and level of social support (friendships and school connectedness). These factors have previously been reported to be associated with bullying. ${ }^{7-14,23-27}$ Interactions of these factors with sex were also tested, and when found significant, the associations with bullying are reported separately for boys and girls.

As in previous reports, SES was defined as the mean of the sample z-scores of maternal education and median family income, according to the 2000 Census tract of the family neighborhood. SAS version 9.2 (SAS Institute, Inc, Cary, NC) was used for all analyses and $\mathrm{p}<0.05$ was considered statistically significant.

\section{RESULTS \\ Demographic and birth data}

The ELBW children did not differ significantly from the NBW children with regards to maternal sociodemographic factors and sex of the child with the exception that the andbiologic mothers of the ELBW children were older than those of the NBW children (Table I). The mean birth weight of the ELBW children was $816 \mathrm{gm}$ and mean gestational age was 26 weeks. Twelve percent of the ELBW children had cerebral palsy and $13 \%$ had an IQ $<70$ at age 14 years compared to $4 \%$ of the NBW children. Their age and current grade were similar (Table I). 


\section{Comparison of bullying between ELBW and NBW children}

Group differences revealed a non-significant trend for higher mean bullying scores among the ELBW compared to NBW children $(\mathrm{p}=0.057)$. The mean bullying score for ELBW boys was significantly higher than that for NBW boys $(\mathrm{p}=0.009)$ but did not differ among ELBW and NBW girls. (Table II). The ELBW boys had higher scores than the NBW boys for the two questions pertaining to being made fun of and to being bullied, whereas scores for ELBW girls vs. NBW girls did not differ significantly for any of the three questions.

\section{Risk factors associated with bullying among the ELBW Children}

Multivariable regression analyses that adjusted for socioeconomic status, race, and sex revealed several significant correlates of the mean bullying score among the ELBW children. These included subnormal IQ, parent report of one or more Functional Limitations, youth report of symptom severity scores of Generalized Anxiety and the Inattentive, Hyperactive, and Combined subtypes of ADHD, and of scores exceeding the DSM IV cutoff for Generalized Anxiety and the Inattentive type of ADHD. Bullying was also significantly associated with less Satisfaction with health, less Comfort, less Risk Avoidance (i.e. more risk taking), more Disorders, and poorer Peer and School Connectedness. There was a significant interaction effect of sex with bullying for the youth report of the symptom severity scores of the Inattentive and Hyperactive types of ADHD, with stronger associations between bullying and these scores among ELBW boys. Poorer Satisfaction with Health was associated with bullying among ELBW boys but not among ELBW girls, and subnormal IQ was associated with bullying among ELBW girls but not among ELBW boys (Table III). The mean bullying score was not associated with birth weight, gestational age, multiple birth, presence of cerebral palsy, subnormal weight, height, obesity, parent report of Generalized Anxiety or ADHD or with any of the sociodemographic factors. The mean bullying score for black vs. white children was $1.7 \pm 2.1$ vs. $1.4 \pm 2.1$ ( $\mathrm{p}=0.18$ ); for children of mothers with less than a high school education vs. high school and above, $1.4 \pm 2.5$ vs.1.6 \pm 2.1 ( $\mathrm{p}=0.33$ ); and for children of unmarried vs. married mothers $1.7 \pm 2.2$ vs. $1.3 \pm 1.9$ $(\mathrm{p}=0.23)$, respectively. The Pearson correlation of the mean bullying score with mean family income was $\mathrm{r}=-0.09(\mathrm{p}=0.24)$.

\section{DISCUSSION}

Certain personal, physical, and behavioral characteristics prevalent among preterm children place them at risk for peer victimization such as bullying. ${ }^{7-14}$ The results of our study reveal that ELBW boys, but not girls, are at increased risk for being bullied compared with other boys born of normal birth weight. Significant correlates of being bullied among the ELBW children included having a subnormal IQ, one or more chronic functional limitations, youth self-reports of symptoms of anxiety and/or ADHD, poor peer relationships, poor school connectedness, and decreased health related quality of life including less satisfaction with health, less comfort, less risk avoidance, and more disorders. Birth weight and gestational age were not significantly associated with bullying. However the range of birth weight and gestational age is limited in an ELBW cohort of children with birth weights $<1 \mathrm{~kg}$. Our results support our hypotheses, with the exception that we did not find a relationship between bullying and abnormal growth.

This is the first report of the occurrence of bullying among ELBW children born in the United States. There have been two previous studies documenting increased rates of bullying in children born preterm. Nadeau undertook a longitudinal study of preterm children of $<29$ weeks gestation in Quebec, Canada. ${ }^{19}$ At age 7 years bullying was assessed by the children's peers in a school setting utilizing the Modified Peer Nomination Inventory and included three questions concerning verbal victimization. After adjusting for weight and 
height, preterm children were found to experience significantly more verbal bullying than NBW controls. Similar to our findings, preterm boys experienced more victimization than control boys. ${ }^{19}$ The higher rates of bullying among preterm children persisted even after excluding children with visible disabilities. The results were confirmed when the children were re-examined at ages 9 and 12 years of age, where, irrespective of gender, preterm children both with and without cerebral palsy experienced more bullying than controls. ${ }^{20}$ These findings support our finding of a lack of a significant relationship of bullying with cerebral palsy. Grindvik, in Norway, compared reports of bullying among very low birth weight (VLBW, $<1.5 \mathrm{~kg}$ ) children to controls using responses to questions in the Strengths and Difficulties Questionnaire. VLBW children reported significantly more bullying than controls (19\% vs. $4 \%$ ) whereas the rates of bullying did not differ significantly according to parents (14\% vs. $5 \%$ ) or teacher reports (9\% vs. $4 \%$ ). Parents, however, reported more bullying among the VLBW children according to one question from the Autism Spectrum Difficulties questionnaire. Gender differences were not reported in this study. ${ }^{21}$ The only other report of bullying among preterm children is that of Johnson from the United Kingdom, who did not find higher rates bullying among 15-16 year old $<29$ week gestation teenagers in mainstream school according to a self reported postal questionnaire concerning health and school performance that included one question on whether or not the child had been bullied. ${ }^{22}$

We found significant differences between the ELBW and NBW boys in the questions pertaining to being made fun of and to being bullied. Verbal and relational bullying, including rumors and rejection, may be considered when the child responds to the question about being made fun of rather than being bullied. This possibly explains why both questions differed between ELBW and NBW boys.

Our finding of an increase in bullying among ELBW boys may be partly due to their poorer neuropsychological functioning and achievement. ${ }^{18}$ The associations between the ELBW children and aspects of health status including self-reported poorer satisfaction with health and comfort, more medical disorders, anxiety and ADHD and with parent reported functional limitations, are in agreement with studies of bullying in normative populations. ${ }^{11,12,14,23-26}$ Of the three risk avoidance subdomains of the CHIP-AE self report, Threats to Achievement was the only subdomain that was significantly but negatively associated with bullying $(\mathrm{r}=-0.29, \mathrm{p}<0.001)$. This subdomain includes questions concerning threatening to hurt or attack someone and trouble concentrating in school or getting things done. Such behaviors may either predispose a child to bully or result from bullying. ${ }^{39} \mathrm{We}$ did not, however, examine whether the ELBW children bullied other children more than the NBW children.

Our findings of a significant association between bullying of the ELBW children and poor friendships and decreased school connectedness are also in agreement with reports of bullying among normative populations of children. 7,40,41 This may associated with the increase in behavioral problems, special health care needs, and poor social functioning prevalent among ELBW children which may result in social exclusion and isolation. ${ }^{15-18,35}$

Obesity and subnormal height are associated with bullying in normative populations, ${ }^{10,11,27,43}$ however this was not evident in our ELBW cohort despite the fact that ELBW children, especially boys, tend to remain shorter than their peers during adolescence. ${ }^{44}$ This finding, together with the lack of association of bullying with cerebral palsy, suggests that bullying of ELBW children may not be associated with visible physical limitations but rather with psychosocial and behavioral difficulties. The higher prevalence of bullying reported among adolescents at greater socioeconomic disadvantage was also not evident in our ELBW population. ${ }^{45}$ 
Strengths of our study include its longitudinal nature, our relatively good followup rate, and multifactorial assessment of the correlates of bullying. Possible limitations include the fact that our results were based on self-reports. Victims of bullying may be disinclined to report their mistreatment by peers and result in an underestimate of these incidents. However, selfreports are considered to be the most reliable measure of bullying ${ }^{2}$ and they have been used in several investigations of the long-term effects of bullying, including a large study of the correlates of bullying among adolescent European children and by other studies of the long term effects of bullying. ${ }^{7,46,47}$ Our assessment of bullying was confined to a few questions and to a limited time period, similar to the other studies of preterm children. ${ }^{17-22}$ Our study identified children by birth weight rather than gestational age. Furthermore our population represents a predominantly hospital based urban population that is not representative of the United States as a whole. Compared to non-participants, the participants in our study had mothers with higher levels of education, comprised more females, and had lower rates of cerebral palsy. Although we adjusted for SES, race, and sex in our analyses, group differences in these factors may have influenced our results. We did not find sociodemographic factors or cerebral palsy to be associated with the mean bullying score. However had more males been included in the study, the mean bullying scores of the total population of ELBW children (males and females) might have differed significantly from that of NBW children.

The results of this study have implications for the future late-adolescent and adult health and psychosocial development of our cohort of ELBW children. ELBW status may be a marker for potential bullying when associated with chronic functional and behavioral problems and among boys. Our findings help characterize bullying victims among ELBW children which may help identify specific subgroups of ELBW children susceptible to bullying so that effective preventative interventions, school based services, or counseling may be implemented to better protect them. ${ }^{5,48,49}$.

\section{Acknowledgments}

We thank Mrs. Kathy Winter, who coordinated the project and participated in the interview of the parents; Ellen Durand and Heather Marcinick research assistants, who tested the children and administered the questionnaires; Sheree Hemphill who developed the REDCap database, Lydia Cartar who participated in the initial data management and analysis and Bonnie Tarantino and Alpher Torres who provided clerical assistance. We had no paid writing assistance.

\section{FUNDING SOURCE}

The study was supported by grants R01 HD 39756, M01 RR000 and ULI RR024989 from the National Institute of Health (NIH). The study sponsors (NIH) had no involvement in the study design, or in the collection, analysis and interpretation of data; in the writing of the manuscript or in the decision to submit the manuscript for publication/

\section{REFERENCES}

1. Olweus, D. Bullying at school: What we know and what we can do. Blackwell Publishers; Oxford, United Kingdom: 1993.

2. Berger KS. Update on bullying at school: Science forgotten? Developmental Review. 2007; 27:90126.

3. Nansel TR, Overpeck M, Pilla RS, et al. Bullying behaviors among US youth: prevalence and association with psychosocial adjustment. JAMA. 2001; 285:2094-2100. [PubMed: 11311098]

4. Sansone RA, Sansone LA. Bully victims: psychological and somatic aftermaths. Psychiatry(Edgemont). 2008; 5:62-64.

5. Hanish LD, Guerra NG. A longitudinal analysis of patterns of adjustment following peer victimization. Dev Psychopathol. 2002; 14:69-89. [PubMed: 11893095] 
6. Gladstone GL, Parker GB, Malhi GS. Do bullied children become anxious and depressed adults? A cross-sectional investigation of the correlates of bullying and anxious depression. J Nerv Ment Dis. 2006; 194(3):201-208. [PubMed: 16534438]

7. Analitis F, Velderman MK, Ravens-Sieberer U, et al. Being bullied: associated factors in children and adolescents 8 to 18 years old in 11 EEuropean countries. Pediatrics. 2009; 123:569-77. [PubMed: 19171624]

8. Hodges EV, Malone MJ, Perry DG. Individual risk and social risk as interacting determinants of victimization in the peer group. Dev Psychol. 1997; 33:1032-9. [PubMed: 9383625]

9. Egan SK, Perry DG. Does low self-regard invite victimization? Dev Psychol. 1998; 34:299-309. [PubMed: 9541782]

10. Lumeng JC, Forrest P, Appugliese DP, et al. Weight status as a predictor of being bullied in third through sixth grades. Pediatrics. Jun; 2010 125(6):e1301-7. [PubMed: 20439599]

11. Sentenac M, Arnaud C, Gavin A, et al. Peer victimization among school-aged children with chronic conditions. Epidemiologic Reviews. Advanced Access Published November 30, 2011.

12. Twyman KA, Saylor CF, Saia D, et al. Bullying and ostracism experiences in children with special health care needs. J Dev Behav Pediatr. 2010; 31:1-8. [PubMed: 20081430]

13. Van Cleave J, Davis MM. Bullying and peer victimization among children with special health care needs. Pediatrics. 2006; 118:e1212-1219. [PubMed: 17015509]

14. Forrest CB, Bevans KB, Riley W, et al. School outcomes of children with special health care needs. Pediatrics. 2011; 128:303-312. [PubMed: 21788226]

15. Hack M, Taylor HG, Schluchter M, et al. Behavioral outcomes of extremely low birth weight children at age 8 years. J Dev Behav Pediatr. 2009; 30:122-130. [PubMed: 19322106]

16. Johnson S, Marlow N. Preterm birth and childhood psychiatric disorders. Pediatr Res. 2011; 69(5 Pt 2):11R-8R.

17. Buck GM, Msall ME, Schisterman EF, et al. Extreme prematurity and school outcomes. Paediatr Perinat Epidemiol. 2000; 14:324-31. [PubMed: 11101019]

18. Taylor HG, Klein N, Drotar D, et al. Consequences and risks of $<1000$-g birth weight for neuropsychological skills, achievement, and adaptive functioning. J Dev Behav Pediatr. 2006; 27:459-69. [PubMed: 17164618]

19. Nadeau L, Tessier R, Lefebvre F, et al. Victimization: a newly recognized outcome of prematurity. Dev Med Child Neurol. 2004; 46:508-13. [PubMed: 15287240]

20. Nadeau L, Tessier R. Social adjustment at school: Are children with cerebral palsy perceived more negatively by their peers than other at-risk children? Disabil Rehabil. 2009; 31:302-8. [PubMed: 18608361]

21. Grindvik AS, Hodøl JS, Vik T, Evensen KA, Skranes J, Brubakk AM, Indredavik MS. Bullying among adolescents with very low birth weight. Acta Paediatr. 2009; 98:1049-1051. [PubMed: 19243568]

22. Johnson A, Bowler U, Yudkin P, Hockley C, Wariyar U, Gardner F, Mutch L. Health and school performance of teenagers born before 29 weeks gestation. Arch Dis Child Fetal Neonatal Ed. 2003; 88:F190-F198. [PubMed: 12719391]

23. Frisén A, Bjarnelind S. Health-related quality of life and bullying in adolescence. Acta Paediatr. 2010; 99:597-603. [PubMed: 20085553]

24. Wynne SL, Joo H. Predictors of school victimization: Individual, familial and school factors. Crime and Delinquency. 2011; 57:458-488.

25. Humphrey JL, Storch EA, Geffken GR. Peer victimization in children with attention-deficit hyperactivity disorder. J Child Health Care. 2007; 11:248-260. [PubMed: 17709359]

26. Reijntjes A, Kamphuis JH, Prinzie P, et al. Peer victimization and internalizing problems in children: a meta-analysis of longitudinal studies. Child Abuse Negl. 2010; 34:244-252. [PubMed: 20304490]

27. Janssen I, Craig WM, Boyce WF, et al. Associations between overweight and obesity with bullying behaviors in school-aged children. Pediatrics. 2004; 113:1187-1194. [PubMed: 15121928] 
28. Hack M, Schluchter M, Andreias L, et al. Change in prevalence of chronic conditions between childhood and adolescence among extremely low-birth-weight children. JAMA. 2011; 306:394401. [PubMed: 21791688]

29. Ravens-Sieberer U, Gosch A, Rajmil L, et al. The KIDSCREEN-52 quality of life measure for children and adolescents: psychometric results from a cross-cultural survey in 13 European countries. Value Health. 2008; 11:645-658. [PubMed: 18179669]

30. Starfield B, Riley AW, Green BF, et al. The adolescent child health and illness profile. A population-based measure of health. Med Care. 1995; 33:553-66. [PubMed: 7739277]

31. Gadow, KD.; Sprafkin, J. Youth's Inventory-4 Manual. Checkmate Plus, LTD; Stony Brook NY: 1999.

32. Bevans KB, Riley AW, Forrest CB. Development of the Healthy Pathways Childreport scales. Qual Life Res. 2010; 19:1195-1214. [PubMed: 20563886]

33. Bearman, PS.; Jones, J.; Udry, JR. The National Longitudinal Study of Adolescent Health: Research design. Carolina Population Center; Chapel, NC: 1997. [Available at http//:www.cpc.unc.edu//projects/addhealth/design.html]

34. Wechsler Abbreviated Scale of Intelligence TM (WASI ${ }^{\mathrm{TM}}$ ). Psychological Corporation; San Antonio, Tx: 1999.

35. Hack M, Taylor HG, Drotar D, et al. Chronic conditions, functional limitations, and special health care needs of school-aged children born with extremely low-birth-weight in the 1990s. JAMA. 2005; 294:318-25. [PubMed: 16030276]

36. Kuczmarski RJ, Ogden CL, Grummer-Strawn LM, et al. CDC growth charts: United States. Adv Data. 2000:314-327.

37. Stein RE, Silver EJ, Bauman LJ. Shortening the questionnaire for identifying children with chronic conditions: what is the consequence? Pediatrics. 2001; 107:E61. [PubMed: 11335782]

38. Gadow, KD.; Sprafkin, J. Adolescent Symptom Inventory-4 Norms Manual. Checkmate Plus, LTD; Stony Brook NY: 1997.

39. Hodges EV, Perry DG. Personal and interpersonal antecedents and consequences of victimization by peers. J Pers Soc Psychol. 1999; 76:677-685. [PubMed: 10234851]

40. Glew GM, Fan MY, Katon W, et al. Bullying, psychosocial adjustment, and academic performance in elementary school. Arch Pediatr Adolesc Med. 2005; 159:1026-1031. [PubMed: 16275791]

41. Hodges EV, Boivin M, Vitaro F, et al. The power of friendship: protection against an escalating cycle of peer victimization. Dev Psychol. 1999; 35:94-101. [PubMed: 9923467]

42. McCormack LA, Laska MN, Gray C, et al. Weight-related teasing in a racially diverse sample of sixth-grade children. J Am Diet Assoc. 2011; 111:431-436. [PubMed: 21338744]

43. Saigal S, Stoskopf BL, Streiner DL, et al. Physical growth and current health status of infants who were of extremely low birth weight and controls at adolescence. Pedaitrics. 2001; 108:407-415.

44. Due P, Merlo J, Harel-Fisch Y, Damsgaard MT, Holstein BE, Hetland J, Currie C, Gabhainn SN, de Matos MG, Lynch J. Socioeconomic inequality in exposure to bullying during adolescence: a comparative, cross-sectional, multilevel study in 35 countries. Am J Public Health. 2009:907-914. [PubMed: 19299676]

45. Sawyer AL, Bradshaw CP, O’Brennan LM. Examining ethnic, gender, and developmental differences in the way children report being a victim of "bullying" on self-report measures. $\mathrm{J}$ Adolesc Health. 2008; 43:106-114. [PubMed: 18639783]

46. Brunstein Klomek A, Marroco F, Kleinman M, Chonfeld IS, Gould MS. Bullying, depression, and suicidality in adolescents. J Am Acad Child Psychiatry. 2007; 46:40-49.

47. Sourander A, Brunstein Klomek A, Ikoned M, Lindroos J, Lundtamo T, Koskelainen M, et al. Psychosocial risk factors associated with cyberbullying among adolescents:a population-based study. Arch Gen Psychiatry. 67:720-728. [PubMed: 20603453]

48. Olweus, D.; Limber, S. The Olweus bullying prevention program: Implementation and evaluation over two decades. In: Jimerson, SR.; Swearer, SM.; Espelage, DL., editors. Handbook of bullying in schools: An international perspective. Routledge; New York, NY: 2010. p. 377-401.

49. Vessey JA, O'Neill KM. Helping students with disabilities better address teasing and bullying situations: a MASNRN study. J Sch Nurs. 2011; 27:139-148. [PubMed: 20956579] 


\section{Table I}

\section{MATERNAL DEMOGRAPHIC RISK FACTORS IN PERINATAL DATA}

\begin{tabular}{|c|c|c|}
\hline & $\begin{array}{c}\text { ELBW } \\
\mathbf{n}=172\end{array}$ & $\begin{array}{l}\text { NBW } \\
n=115\end{array}$ \\
\hline \multicolumn{3}{|l|}{ Maternal Demographic Data } \\
\hline Age (years) ${ }^{\circ}$ & $44 \pm 7$ & $41 \pm 7^{c}$ \\
\hline Married & $75(44 \%)$ & $63(55 \%)$ \\
\hline \multicolumn{3}{|l|}{ Education } \\
\hline$<$ High school & $13(7.6 \%)$ & $12(10.4 \%)$ \\
\hline \multicolumn{3}{|l|}{ Race } \\
\hline White & $67(39 \%)$ & $39(34 \%)$ \\
\hline Black & $105(61 \%)$ & $76(66 \%)$ \\
\hline Family income (dollars $\pm \mathrm{SD} \neq$ & $44 \pm 19$ & $40 \pm 19$ \\
\hline \multicolumn{3}{|l|}{ Perinatal Data } \\
\hline Birth weight (gm $\pm \mathrm{SD})$ & $816 \pm 123$ & $3260 \pm 524$ \\
\hline Gestational age $(w k \pm S D)$ & $26 \pm 2$ & $\geq 37$ \\
\hline Female sex & $109(63 \%)$ & $73(64 \%)$ \\
\hline Multiple birth & $30(17 \%)$ & ----- \\
\hline \multicolumn{3}{|l|}{ Developmental Status } \\
\hline Age Years \pm SD & $14.7 \pm 0.7$ & $14.8 \pm 0.7$ \\
\hline Grade level & $8.6 \pm 0.9$ & $8.8 \pm 0.8$ \\
\hline $\mathrm{IQ}<70$ & $23(13 \%)$ & $4(4 \%)^{b}$ \\
\hline Cerebral palsy & $20(12 \%) \neq$ & ----- \\
\hline \multicolumn{3}{|c|}{$\begin{array}{l}\text { Unless otherwise stated refers to primary caregiver for which } 1163(95 \%) \text { of the } \\
\text { Biological and adoptive mothers only }\end{array}$} \\
\hline \multicolumn{3}{|c|}{ Mean of median family income (US $\$ \times 1000$ ) according to the 2000 Census tract neighborhood in which the families lived. } \\
\hline \multicolumn{3}{|c|}{$b_{\mathrm{p}<0.01}$} \\
\hline
\end{tabular}


Table II

COMPARISON OF MEAN BULLYING SCORES BETWEEN EXTREMELY LOW BIRTH WEIGHT (ELBW) AND NORMAL BIRTH WEIGHT (NBW) CHILDREN

\begin{tabular}{|c|c|c|c|c|}
\hline & $\begin{array}{c}\text { Extremely Low } \\
\text { Birth Weight }^{+}\end{array}$ & $\begin{array}{c}\text { Normal } \\
\text { Birth Weight }^{+}\end{array}$ & $\begin{array}{c}\text { Difference in } \\
\text { Adjusted } \\
\text { means }^{+}(95 \% \text { CI })\end{array}$ & $\mathbf{p}$ \\
\hline $\begin{array}{l}\text { Total } \\
\text { population }\end{array}$ & $\mathrm{n}=\mathbf{1 7 2}$ & $\mathrm{n}=\mathbf{1 1 5}$ & & \\
\hline Mean \pm SD & $1.56 \pm 2.10$ & $1.16 \pm 1.43$ & $\begin{array}{c}0.43(-0.01,0.87) \\
\#\end{array}$ & 0.057 \\
\hline $\begin{array}{l}\text { Median } \\
\text { (range) }\end{array}$ & $1(0-10)$ & $0(0-4)$ & & \\
\hline Boys & $n=63$ & $n=42$ & & \\
\hline Mean \pm SD & $1.94 \pm 2.36$ & $0.91 \pm 1.27$ & $1.07(0.28,1.86)^{\circ}$ & 0.009 \\
\hline $\begin{array}{l}\text { Median } \\
\text { (range) }\end{array}$ & $1(0-10)$ & $0(0-4)$ & & \\
\hline Girls & $n=109$ & $n=73$ & & \\
\hline Mean \pm SD & $1.34 \pm 1.89$ & $1.30 \pm 1.51$ & $0.15(-\underset{0}{0.37}, 0.67)$ & 0.582 \\
\hline $\begin{array}{l}\text { Median } \\
\text { (range) }\end{array}$ & $1(0-8)$ & $0(0-6)$ & & \\
\hline
\end{tabular}

${ }^{+}$Mean of 3 questions from KIDSCREEN bullying dimension ${ }^{23}$. Higher scores indicate more bullying.

${ }^{\#}$ Adjusted for socioeconomic status, race and sex.

Adjusted for socioeconomic status and race. 
Table III

COMPARISON OF THE BULLYING SCORES OF THE THREE QUESTIONS PERTAINING TO BULLYING BETWEEN EXTREMELY LOW BIRTH WEIGHT (ELBW) AND NORMAL BIRTH WEIGHT (NBW) CHILDREN

\begin{tabular}{|c|c|c|c|c|c|c|c|c|c|}
\hline & \multicolumn{3}{|c|}{ TOTAL POPULATION } & \multicolumn{3}{|l|}{ BOYS } & \multicolumn{3}{|l|}{ GIRLS } \\
\hline & $\begin{array}{l}\text { ELBW } \\
(n=172)\end{array}$ & $\begin{array}{l}\text { NBW } \\
(n=115)\end{array}$ & $\mathbf{P}^{\#}$ & $\begin{array}{l}\text { ELBW } \\
(n=63)\end{array}$ & $\begin{array}{l}\text { NBW } \\
(n=42)\end{array}$ & $\mathbf{P}^{\circ}$ & $\begin{array}{l}\text { ELBW } \\
(n=109)\end{array}$ & $\begin{array}{l}\text { NBW } \\
(n=73)\end{array}$ & $\mathbf{P}^{\circ}$ \\
\hline \multicolumn{10}{|c|}{ Individual questions } \\
\hline \multicolumn{10}{|c|}{$\begin{array}{l}\text { Have you ever been afraid of } \\
\text { other girls/boys? }\end{array}$} \\
\hline Mean Score \pm SD & $0.27 \pm 0.56$ & $0.29 \pm 0.54$ & 0.859 & $0.32 \pm 0.62$ & $0.17 \pm 0.44$ & 0.159 & $0.25 \pm 0.53$ & $0.36 \pm 0.59$ & 0.252 \\
\hline \multicolumn{10}{|c|}{$\begin{array}{l}\text { Have other girls/boys made } \\
\text { fun of you? }\end{array}$} \\
\hline Mean Score \pm SD & $0.93 \pm 1.16$ & $0.68 \pm 0.79$ & 0.029 & 1. $10 \pm 1.2$ & $0.5 \pm 0.89$ & 0.011 & $0.84 \pm 1.13$ & $0.74 \pm 0.73$ & 0.268 \\
\hline \multicolumn{10}{|c|}{$\begin{array}{l}\text { Have other boys and girls } \\
\text { bullied you }\end{array}$} \\
\hline Mean Score \pm SD & $0.36 \pm 0.86$ & $0.19 \pm 0.53$ & 0.064 & $0.52 \pm 0.10$ & $0.17 \pm 0.44$ & 0.030 & $0.26 \pm 0.79$ & $0.21 \pm 0.58$ & 0.473 \\
\hline
\end{tabular}

Higher scores indicate more bullying.

${ }^{\#}$ Adjusted for socioeconomic status, race and sex.

Adjusted for socioeconomic status and race 
Table IV

\section{CORRELATES OF BULLYING AMONG EXTREMELY LOW BIRTH WEIGHT ADOLESCENTS}

\begin{tabular}{|c|c|c|}
\hline Risk Factors for Bullying & $\begin{array}{l}\text { Mean Bullying } \\
\text { Score } \pm \text { SD } \\
\text { or Pearson } \\
\text { correlation }\end{array}$ & Beta $(95 \%$ CI $)$ \\
\hline \multicolumn{3}{|l|}{ Perinatal Data } \\
\hline Birth weight (kg) & -0.02 & $-0.39(-2.94,2.16)$ \\
\hline 268 Gestational age (wks) & 0.07 & $0.10(-0.07,0.26)$ \\
\hline \multicolumn{3}{|l|}{ Multiple births } \\
\hline Yes $(n=30)$ & $1.0 \pm 1.2$ & $-0.48(-1.38,0.42)$ \\
\hline No $(n=142)$ & $1.7 \pm 2.2$ & \\
\hline \multicolumn{3}{|l|}{ Cerebral palsy } \\
\hline Yes $(n=152)$ & $1.8 \pm 2.6$ & $0.27(-0.71,1.26)$ \\
\hline No $(n=20)$ & $1.5 \pm 2.0$ & \\
\hline \multicolumn{3}{|l|}{$\mathbf{I Q}^{1}$} \\
\hline Male: $<70(n=9)$ & $1.7 \pm 3.0$ & $-0.34(-1.79,1.12)$ \\
\hline$\geq 70(\mathrm{n}=54)$ & $2.0 \pm 2.3$ & \\
\hline Female: $<70(n=14)$ & $2.8 \pm 2.8$ & $1.55(0.36,2.74)^{\mathrm{a}}$ \\
\hline$\geq 70(\mathrm{n}=95)$ & $1.1 \pm 1.6$ & \\
\hline \multicolumn{3}{|l|}{ Functional limitations } \\
\hline One or more $(n=75)$ & $2.1 \pm 2.5$ & $0.72(0.06,1.38)^{\mathrm{a}}$ \\
\hline None $(n=97)$ & $1.2 \pm 1.6$ & \\
\hline \multicolumn{3}{|l|}{ Youth Behavior Report } \\
\hline \multicolumn{3}{|c|}{ Symptom Severity Scores } \\
\hline Generalized anxiety & 0.33 & $0.17(0.11,0.24)^{\mathrm{c}}$ \\
\hline \multicolumn{3}{|l|}{ ADHD } \\
\hline Inattentive $^{2}$ : Male & 0.52 & $0.33(0.21,0.45)^{\mathrm{c}}$ \\
\hline Female & 0.12 & $0.09(0.00,0.18)^{\mathrm{a}}$ \\
\hline Hyperactive & 0.21 & $0.11(0.03,0.19)^{\mathrm{b}}$ \\
\hline Combined $^{3}:$ Male & 0.48 & $0.17(0.09,0.24)^{\mathrm{c}}$ \\
\hline Female & 0.22 & $0.05(0.00,0.10)^{\mathrm{a}}$ \\
\hline \multicolumn{3}{|l|}{ DSM IV Cut-off Score } \\
\hline \multicolumn{3}{|l|}{ Generalized anxiety } \\
\hline Yes $(n=11)$ & $3.3 \pm 4.0$ & $3.01(1.82,4.20)^{\mathrm{c}}$ \\
\hline No $(N=158)$ & $1.5 \pm 2.0$ & \\
\hline \multicolumn{3}{|l|}{ ADHD } \\
\hline \multicolumn{3}{|l|}{ Inattentive } \\
\hline Yes $(n=5)$ & $4.8 \pm 4.3$ & $2.14(0.18,4.09)^{\mathrm{a}, 4}$ \\
\hline No $(n=164)$ & $1.4 \pm 1.9$ & \\
\hline \multicolumn{3}{|l|}{ Hyperactive } \\
\hline Yes $(n=5)$ & $3.3 \pm 1.7$ & $1.61(-0.46,3.69)$ \\
\hline No $(n=164)$ & $1.5 \pm 2.1$ & \\
\hline
\end{tabular}

Early Hum Dev. Author manuscript; available in PMC 2014 May 01. 


\begin{tabular}{|c|c|c|}
\hline Risk Factors for Bullying & $\begin{array}{l}\text { Mean Bullying } \\
\text { Score } \pm \text { SD } \\
\text { or Pearson } \\
\text { correlation }\end{array}$ & Beta $(95 \%$ CI $)$ \\
\hline \multicolumn{3}{|l|}{ Combined } \\
\hline Yes $(n=1)$ & $5.5 \pm 0.0$ & NA (only 1 child) \\
\hline No $(n=168$ & $1.5 \pm 2.0$ & \\
\hline \multicolumn{3}{|l|}{ Parent Behavior Report } \\
\hline \multicolumn{3}{|c|}{ Symptom Severity Scores } \\
\hline Generalized anxiety & -0.00 & $-0.01(-0.11,0.10)$ \\
\hline Inattentive & 0.15 & $0.04(-0.01,0.09)$ \\
\hline Hyperactive & 0.06 & $-0.05(-0.13,0.02)$ \\
\hline Combined & 0.07 & $0.00(-0.03,0.04)$ \\
\hline \multicolumn{3}{|l|}{ DSM IV Cut-off Score } \\
\hline \multicolumn{3}{|l|}{ Generalized anxiety } \\
\hline Yes $(n=3)$ & $3.3 \pm 4.0$ & $1.95(-0.41,4.30)$ \\
\hline No $(n=166)$ & $1.5 \pm 2.0$ & \\
\hline \multicolumn{3}{|l|}{ ADHD } \\
\hline \multicolumn{3}{|l|}{ Inattentive } \\
\hline Yes $(n=20)$ & $1.6 \pm 2.2$ & $-0.04(-1.01,0.93)$ \\
\hline No $(n=149)$ & $1.5 \pm 2.0$ & \\
\hline \multicolumn{3}{|l|}{ Hyperactive } \\
\hline Yes $(n=4)$ & $0.5 \pm 0.6$ & $-1.10(-3.20,1.00)$ \\
\hline No $(n=165)$ & $1.6 \pm 2.1$ & \\
\hline \multicolumn{3}{|l|}{ Combined } \\
\hline Yes $(n=4)$ & $0.5 \pm 0.6$ & $-1.10(-3.20,1.00)$ \\
\hline No $(n=165)$ & $1.6 \pm 2.1$ & \\
\hline \multicolumn{3}{|c|}{ Health Status-CHIP-AE (mean \pm SD) } \\
\hline - Satisfaction ${ }^{4}$ : males & -0.46 & $-2.77(-4.09,-1.45)^{\mathrm{c}}$ \\
\hline Females & -0.07 & $-0.19(-0.95,0.56)$ \\
\hline - Comfort & -0.26 & $-1.23(-1.94,-0.52)^{\mathrm{c}}$ \\
\hline - Resilience & -0.17 & $-0.69(-1.44,0.06)$ \\
\hline - Achievement & -0.16 & $-0.48(-1.03,0.07)$ \\
\hline - Risk avoidance & -0.23 & $-1.51(-2.65,-0.38)^{b}$ \\
\hline - Disorders & -0.38 & $-2.76(-3.88,-1.64)^{\mathrm{c}}$ \\
\hline
\end{tabular}

